Article

\title{
The Sustainability Performance of Reinforced Concrete Structures in Tunnel Lining Induced by Long-Term Coastal Environment
}

\author{
Zhiqiang Zhang ${ }^{1,2}$, Ruikai Gong ${ }^{1,2}$, Heng Zhang ${ }^{1,2, *}$ and Wanping $\mathrm{He}^{1}$ \\ 1 School of Civil Engineering, Southwest Jiaotong University, Chengdu 610031, China; \\ clark@swjtu.edu.cn (Z.Z.); gongruikai1@163.com (R.G.); hwp940523@163.com (W.H.) \\ 2 Key Laboratory of Transportation Tunnel Engineering, Ministry of Education, Southwest Jiaotong University, \\ Chengdu 610031, China \\ * Correspondence: tunnelzh@home.swjtu.edu.cn; Tel.: +86-028-8763-4386
}

Received: 25 March 2020; Accepted: 9 May 2020; Published: 12 May 2020

check for updates

\begin{abstract}
At present, the damage caused by steel corrosion to structures has become a serious problem all over the world. In order to study the mechanical behaviors of tunnel lining structure system under the corrosive environment to rebars, first, the bending tests were performed to investigate the crack propagation behavior and structural bearing capacity of the reinforced concrete bending members degraded by corrosion. Secondly, the pull-out tests were performed to investigate the degradation of bonding strength between corroded rebars and the concrete. Finally, on the basis of the findings from the pull-out tests, a 3-D finite element bond-slip model of reinforced concrete lining structure has been established to simulate the changes of bearing capacity and durability of tunnel reinforced concrete lining under different corrosion degrees. The research has revealed: Rebar corrosion is the most important factor affecting concrete and steel corrosion. As the conversion rust rate increases, the ultimate drawing force continues to decrease. With the increase of the corrosion rate, the deflection of the specimen when it is destroyed becomes smaller, the cracking load becomes smaller and the bearing capacity also decreases. As the degree of corrosion increases, the overall deformation of the tunnel increases, and the overall safety of the lining structure decreases. The corner position is the most prone to problems after the lining structure is corroded, so pay more attention. As well, the safety of the lining structure will be basically lost when the final corrosion rate of the steel bars is greater than $30 \%$. The findings of this research can be used to evaluate the corrosion degree of tunnel reinforced concrete lining structure and support the durability design of new tunnel concrete lining structure.
\end{abstract}

Keywords: coastal environment; tunnel engineering; lining structure; steel corrosion; bond-slip

\section{Introduction}

With the social and economic development and the continuous improvement of people's requirements for quality of life, the scale and quantity of traffic and the engineering construction projects in China tend to increase on the whole [1-4]. At present, China has developed into one of the countries with the largest scale, the largest number, the most complex structural forms and the most complex construction technologies of tunnels and underground projects in the world [5-9]. Both the tunnel construction process and the operation stage are facing great challenges [10-12]. Reinforced concrete structure has been the first choice for lining structures of tunnels in offshore areas due to their advantages such as high rigidity, high bearing capacity, easy placement, economical cost, and wide application. However, during the operation of the offshore tunnels, due to the combined action of environmental and load factors, the corrosion of the tunnel reinforced concrete lining structures 
becomes more and more serious and the performance of the lining structures decreases continuously as the service life proceeds, and eventually the lining structures will be damaged, which leads to a substantial increase in the maintenance and operation costs of the lining structures and constitutes safety problems. The failures of concrete structures caused by rebar corrosion is a consequential and urgent problem to be solved, and also an important subject for durability research into reinforced concrete structures. Therefore, it is of great engineering significance to investigate the impact of the corrosion of the tunnel lining structures in offshore environment on their durability and bearing capacity [13-15].

The current research on corroded reinforced concrete structures mainly focuses on two aspects: The mechanical properties of rebars in corrosive environment and the overall performance of reinforced concrete structures in corrosive environment. The research on the impacts of corrosive environment on the properties of rebars can be divided into two directions: first, the experiments to investigate the mechanical properties of corroded rebars and the qualitative description and research of constitutive model; second, based on the findings from those experiments, the regression formula of the degradation of the mechanical properties of corroded rebars is analyzed and summarized. Yuan et al. $[16,17]$ studied the mechanical properties of rebars with different corrosion conditions through comparative analysis of findings from laboratory tests and results from numerical simulation. Zhang et al. [18] revealed the regression formulas of such mechanical characteristics as the ultimate strength, elastic modulus, yield strength and ultimate strain, and the corrosion ratio of the of corroded rebars through mechanical experiments on 35 corroded rebars in natural state, 76 corroded rebars obtained from actual structure members and 156 corroded rebars of which the corrosion is accelerated by electric current in the room. Hui et al. [19] showed the statistical formulas of yield strength, tensile strength, and corrosion ratio of corroded rebars through a large number of mechanical tests on corroded rebars. Blomfors [20] modified the FIB model code based on the local bond stress-slip relationship to accommodate the corrosion effect, and further established a model to assess the anchorage capacity of corroded rebars. Liu et al. [21] clarified a statistical model of rebar corrosion through five years of outdoor tests, which takes into account the $\mathrm{CI}$ content, temperature, concrete resistance and corrosion time. Based on the principles of electrochemical reaction, mass conservation law and Fick diffusion law, Bazantl [22] proposed a Bzant model specific to reinforced structures in marine environment, which accommodates the effect of concentration polarization. The indoor rapid tests on corroded rebars can be completed by artificial simulation of corrosive environment or by electric current. When the corrosion ratio is small, the corrosion has little effect on mechanical properties of corroded rebars; when the corrosion ratio is large, the yield strength, ultimate strength, and ultimate elongation of corroded rebars decrease. Based on this research, this paper uses the method of electrochemical corrosion to accelerate rebar corrosion, and then to study the performance of rebars under different corrosion degrees.

As for the overall structural performance of reinforced concrete structures, the laboratory test analysis and finite element simulation analysis are generally used [23-27]. The vast majority of scholars and engineering experts combine the two approaches and verify the results from one with that from the other, so as to obtain conclusions and measures that are more satisfactory in meeting the needs of the actual projects [28-31]. Fan et al. [32,33] adopted the "Replacing Structural Members" test method to conduct tests and draw the conclusion that the main factors affecting the bond strength between rebars and concrete are the corrosion ratio of rebar and the performance of concrete after corrosion. Yuan et al. [34] studied the degradation mechanism of structural properties of corroded reinforced concrete beams through tests and established the degradation models of stress-strain relationship of corroded rebars and bond stress-slip relationship between corroded rebars and concrete. In the laboratory, Oksada [35] conducted tests by applying accelerating corrosion to beam test pieces in laboratory until longitudinal cracks occurred. The results showed that the bearing capacity of corroded reinforced concrete beams decreased significantly, and the strength decreased sharply when repeated loads were applied. Castel [36] carried out mechanical experiments on corroded rebars and concluded that the prediction of bearing capacity of corroded reinforced concrete members should first based 
on the loss ratio of section of corroded rebars and the loss ratio of bonding force of two kinds of materials. Berra [37] applied temperature stress to realize the effect of the volume expansion of corrosion products based on the principle of thermal expansion and cold contraction and predicted the bond-slip relationship between rebars and concrete by synthesizing various constraints and the positions of rebars.

Through a large number of tests and analysis, we can basically draw the main factors that affect the bond strength between rebars and concrete: When the rebars is corroded to a certain degree, its corrosion products remain in the gap between rebars and concrete. When the corrosion ratio is small, these chips are helpful to the bonding performance. However, a large amount of these chips will directly affect the friction coefficient between the two types of materials and are several times the volume of the original rebar, so that the concrete structure around the rebar is subjected to hoop tension. When the amount of corrosion products accumulates to a certain degree, and the expansion force generated exceeds the ultimate tensile strength of concrete, the concrete around rebars will have longitudinal cracks, resulting in the loss of the chemical bonding force between rebars and concrete. When the crack develops to penetrate the protective layer, the concrete of protective layer begins to fall off, so that the rebar loses its restraint and protection, and the mechanical bite force is also lost. Meanwhile, the rebar is also completely exposed to external environment, which accelerates the corrosion, and finally the reinforced concrete structure building loses its durability and is destroyed.

The abovementioned activities indicate that the research on the properties of corroded reinforced concrete materials and the overall structure has achieved fruitful results, and the outcomes have found wide applications in practical projects [38-43]. However, few is on the durability and bearing capacity of reinforced concrete lining structure. The Yanlangshan Tunnel was taken as the research subject in this paper, which is located in Zhuhai Airport Expressway, Guangdong Province, in China. The tunnel is located in the offshore position. After long-term operation, the possibility of corrosive water appears in the surrounding strata is higher. The supporting structure is almost immersed in corrosive water, and the corrosion deterioration of concrete structure is very easy to occur. In view of this, firstly, crack propagation behavior and structural bearing capacity of reinforced concrete bending members degraded by corrosion were obtained through bending tests. Secondly, the degradation of bonding strength between corroded rebars and concrete is analyzed through the pull-out test of rebars. Based on this, a 3-D finite element bond-slip model of reinforced concrete lining structures is established. Finally, based the results from numerical simulations, the overall structural performance changes and ultimate corrosion ratio caused by rebar corrosion under different surrounding rock pressure loads were analyzed. The research results reveal the mechanical behaviors of tunnel lining structure support system degraded by corrosion, which are of important guiding significance and application value for the research of tunnel engineering durability.

At present, the research on the influence of corrosion of steel bars on performance is mainly divided into two directions: First, the mechanical properties of corroded steel bars and the qualitative description and research of constitutive models; second, on the basis of experiments, the mechanical properties of corroded steel bars are analyzed and summarized deteriorated regression formula [44]. The focus is on studying changes in the properties of a single material. This article is based on the previous research, focusing on the effect of steel corrosion on the overall structure of the concrete structure, and applied the research to practical engineering problems. Based on indoor experiment, the numerical simulation calculations are mutually confirmed in this paper to obtain the general laws affecting the durability and bearing capacity of reinforced concrete structure. The specific research contents are:

(1) Accelerated by electric current, the corrosion process and hazards of rebars are explored. The corrosion degree of reinforced concrete specimens caused by different concrete labels, protective layer thickness, and rebar specifications is also compared; 
(2) After conducting electrified accelerated corrosion on the test pieces of different concrete labels, protective layer thickness, and rebar specifications, the eccentric compression method is used to test structural bearing capacity, as well as flexural strength, deflection, and concrete adhesion.

(3) Based on the indoor test law of corrosion effects, the change of structural bearing capacity of the tunnel secondary lining under different degrees of corrosion is simulated through the numerical simulation software such as ANSYS with the adhesive force degradation model. The law of lining structure bearing capacity with different corrosion ratios under the pressure of surrounding rock and the law of concrete protective layer crack development are obtained.

\section{Compression-Bending Performance of Corroded Reinforced Concrete Structures}

The main structure in tunnel engineering is the reinforced concrete lining. In its long-term operation process, due to the corrosion of the external environment and the deterioration of the material itself, the corrosion damage of the internal steel bars will generally occur, which will cause serious damage to the structure itself and seriously affect the durability of the structure. Since reinforcement corrosion in reinforced concrete components is a complete electrochemical process, electrochemical testing is an effective way to accurately reflect its essential process. Its advantages are fast test speed, high sensitivity, continuous tracking, and in-situ testing. Therefore, it is of great significance to study the crack propagation and deformation of lining through laboratory tests under corrosive conditions. However, due to the large size of the lining structure, it is impossible to carry out full-size accelerated corrosion test, and it is difficult to meet the high requirements for the loading equipment. Comprehensively considering the action mode and mechanical state of the tunnel lining structure, as well as the existing test conditions and operation level, the reinforced concrete compression-bending members are chosen as the simulation test pieces to study the durability of the tunnel lining structure.

\subsection{Materials}

The concrete composition of the experiment is based on the concrete of Zhuhai project, and the relevant data are all based on the actual data of Zhuhai project. The grade design of plain concrete is C30 (compressive strength is $30 \mathrm{MPa}$ ), and mixture proportions are listed in Table 1. Cementitious materials made from P.O42.5R cement and Class I Fly Ash were employed in the test, and the water-cement ratio in the mix proportions was 0.45 . The coarse aggregate is gravel with a maximum particle size of $31.5 \mathrm{~mm}$ and the fine aggregate is natural river sand.

Table 1. Mix proportions.

\begin{tabular}{ccccccc}
\hline \multirow{2}{*}{ Concrete Grade } & \multirow{2}{*}{ W/B } & \multicolumn{5}{c}{ Unit Weight $\left.\mathbf{( k g} / \mathbf{m}^{\mathbf{3}}\right)$} \\
\cline { 3 - 7 } & & Cement & Water & Fly Ash & Fine Aggregate & Coarse Aggregate \\
\hline C30 & 0.45 & 309 & 164 & 55 & 1048 & 824 \\
\hline
\end{tabular}

\subsection{Compression-Bending Test Scheme}

According to the cover depth and the size of reinforcing bar, the specimens are divided into four groups, 12 specimens in each group. The details of the specimens are listed in Table 2. For each test specimens, the specimens no. is named after the cover depth, the reinforcing bar dimension, in which the C30 denotes the grade design of plain concrete, the number 35 (or 50) represents the cover depth, the second number 10 (or 14) represents the reinforcing bar diameter. For example, specimen C30-35-10 refers to a specimen with $35 \mathrm{~mm}$ cover depth, $10 \mathrm{~mm}$ reinforcing bar diameter. 
Table 2. Details of test specimens.

\begin{tabular}{ccccc}
\hline Beam no. & $\begin{array}{c}\text { Specimens Length L } \\
(\mathbf{m m})\end{array}$ & $\begin{array}{c}\text { Specimens Width W } \\
\mathbf{( m m )}\end{array}$ & $\begin{array}{c}\text { Cover Depth C } \\
\mathbf{( m m )}\end{array}$ & $\begin{array}{c}\text { Reinforcing Bar } \\
\text { Dimension } \\
\mathbf{D}(\mathbf{m m})\end{array}$ \\
\hline C30-35-10 & 200 & 200 & 35 & 10 \\
C30-35-14 & 200 & 200 & 35 & 14 \\
C30-50-10 & 200 & 200 & 50 & 10 \\
C30-50-14 & 200 & 200 & 50 & 14 \\
\hline
\end{tabular}

The sizes of the reinforced concrete compression-bending test pieces used in this research are as shown in Figures 1 and 2, and the concrete casting mold is as shown in Figure 3. The concrete beams are equipped with sufficient stirrups to ensure the bending failure of the beams instead of shear failure. After the curing of test piece is completed and the initial corrosion current density is determined, the anode is started to pass the current of the specified strength and time. This process is implemented by an ammeter and a DC power supply. The ammeter is used to measure the current. The concrete specimen is placed in a container containing $5 \% \mathrm{NaCl}$ solution, so the bottom of specimen can just be in contact with water. The direction of current flow is adjusted, so the rebar in concrete beam act as anodes, and the stainless steel plates, which covers all sides of the test piece, placed on concrete beams act as cathodes. This arrangement makes the current uniform throughout the entire length of rebar.

In this test, the corrosion of reinforced concrete members is accelerated by current in groups, and the grouping is based on time of applying a constant current. The time of applying the constant current is different, which leads to a big difference in the degree of component corrosion. In the test results, we assume the degree of component corrosion which has not been accelerated by the current is zero, and the required results are obtained by comparing them with the results of each group $[45,46]$.
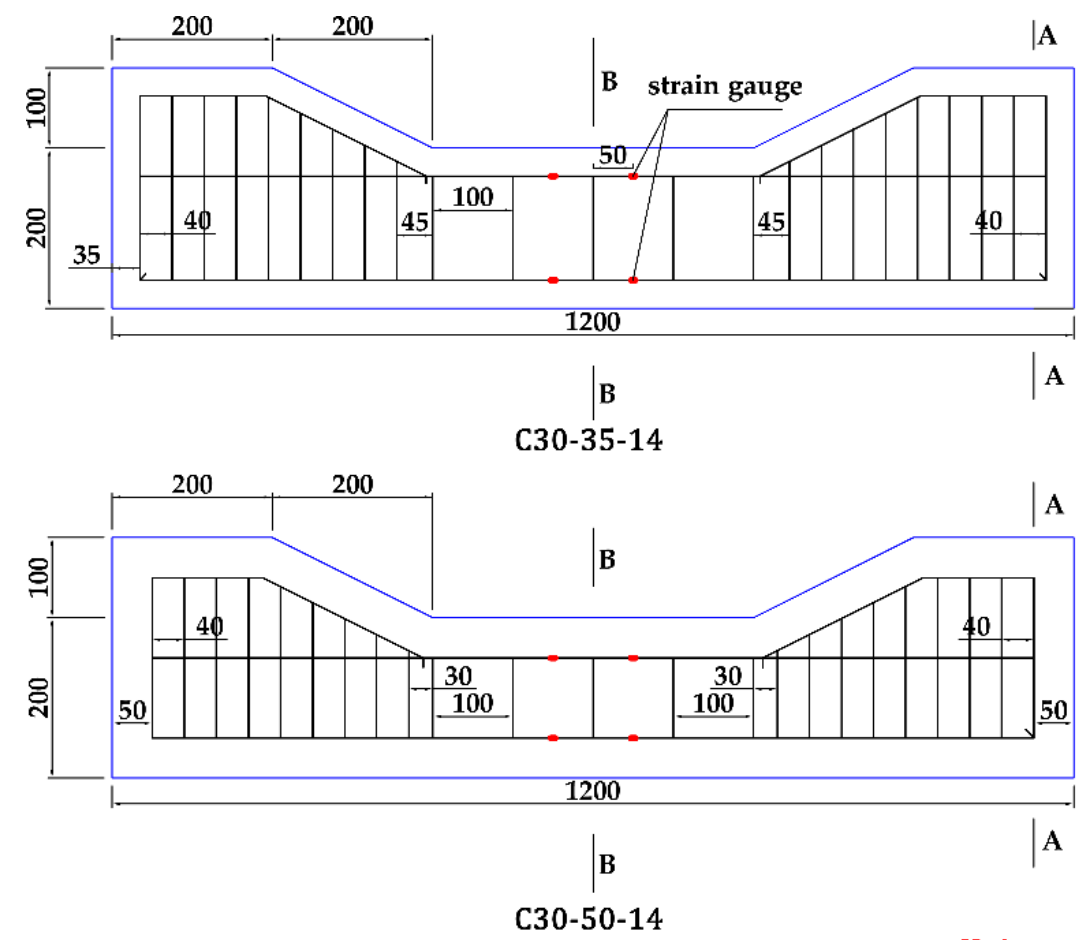

Unit: mm

Figure 1. Reinforced Concrete Compression-Bending Member Elevation Size and Steel Rebar Distribution Diagram. 


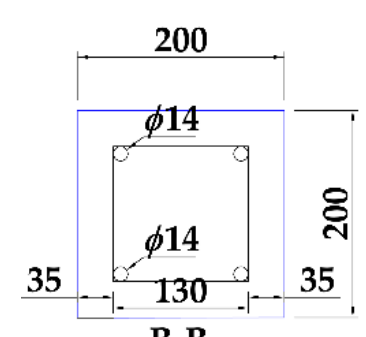

B-B

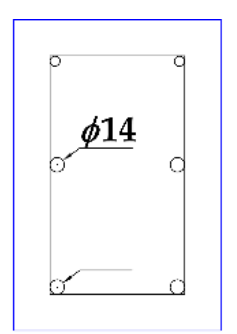

A-A

C30-35-14

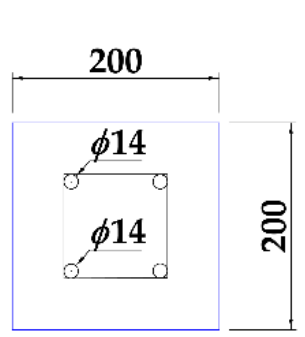

B-B

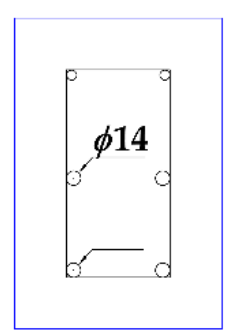

A-A

C30-50-14

Unit: $\mathrm{mm}$

Figure 2. Reinforced Concrete Compression-Bending Member Section Size and Steel Rebar Distribution Diagram.

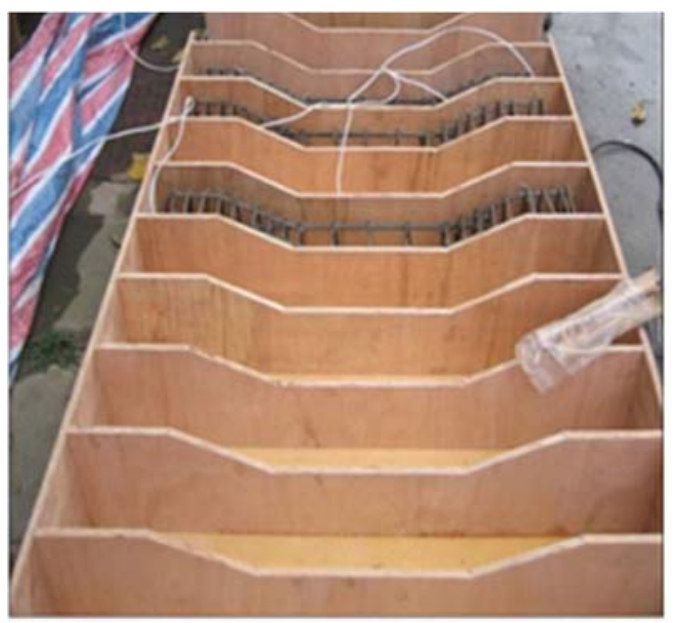

Figure 3. Mold of Compression-Bending Test Pieces.

As an eccentric compressive stress needs to be applied to the piece in this test, to simulate the compression-bending mode of the member, it is required to apply a line load to the member. Based on the preliminary preparations, in order to ensure that the failure mode of the members is mainly the yield of steel bars, it is required to apply the large eccentric compression to the members. Therefore, the compression eccentricity of the members is set as $110 \mathrm{~mm}$, and the required line load is realized by the shaft support. The loading equipment used is $200 \mathrm{~T}$ hydraulic loading test machine as shown in Figure 4. Due to the limitation of test conditions, this test is conducted mainly to study the effect of corrosion of steel bars on deterioration of the overall performance of the members. Therefore, in the loading failure process of the members, a large eccentricity is applied to the members, so that when reaching the ultimate state, the members will be subjected to failure resulting from the tensile yield of the internal tensile steel bars, i.e. the large eccentricity failure. Thus, the deterioration of the concrete materials caused by galvanic corrosion is neglected to ensure that the members are not damaged due to crushing of concrete in the compression zone. 


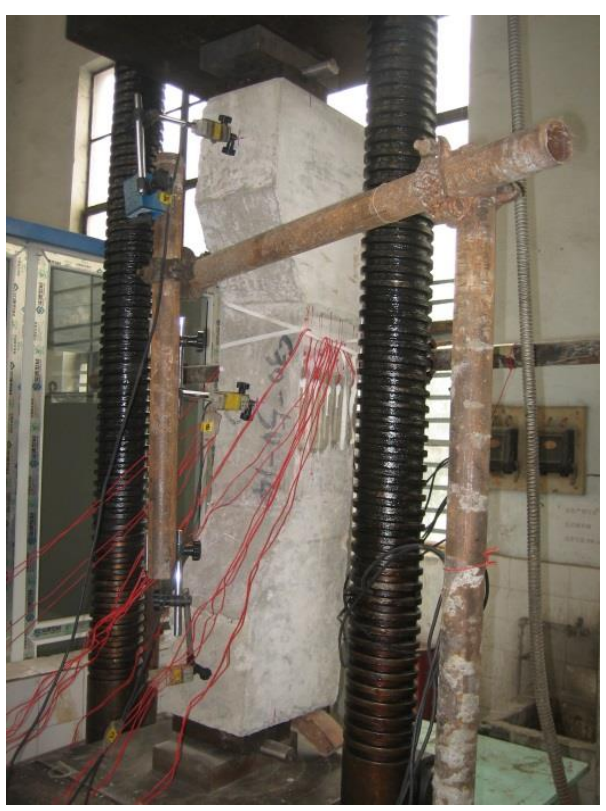

(a)

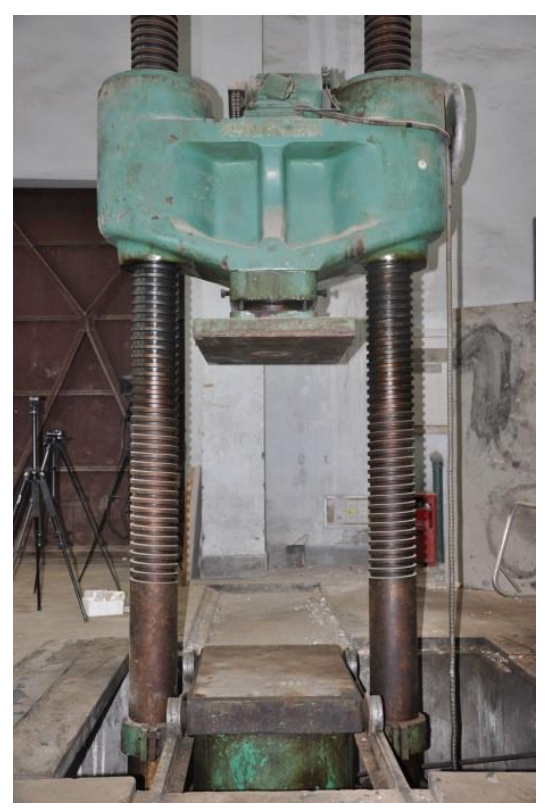

(b)

Figure 4. Loading Device for the Test. (a): Side view of loading device; (b): Front view of loading device

Since the linear polarization method in the electrochemical method for testing rebar corrosion in concrete components has strict requirements on the accuracy of instruments, the Corr Test (corrosion electrochemical test system) is selected for this test to complete the corrosion rate test [47].

In order to test the strain value in the middle of the concrete, five paper-based strain gauges are arranged at both sides of the middle part of the concrete, respectively, in the tension and compression zones of the concrete (as shown in Figure 5). To test the lateral displacement of the members, three displacement meters are arranged at the front and back sides of the members, which are located at the upper and lower surface of the test piece at a distance of $10 \mathrm{~cm}$ and in the middle of the test piece, respectively, so as to study the deformation performance of the member under loading and to compare the changes before and after corrosion (as shown in Figure 5). The measurement with the displacement meters is not only helpful to obtain the lateral displacement change of the member, but also helpful to accurately estimate the ultimate bearing capacity of the member, that is, if the load increases slowly or even decreases, while the displacement value still rises sharply, then this load can be considered as the ultimate value of the member. Also, the test shows the structural capacity under compression with large eccentricity.

The compression eccentricity of the component is $110 \mathrm{~mm}$, and the lateral displacement of the component is tested. Before the performance is officially loaded, the component is preloaded twice, graded to $60 \mathrm{kN}$, and then unloaded to zero step by step to eliminate the impact of the bearing offset and eccentricity on the bearing of the component in order to obtain more accurate test data. After pre-loading, the load is graded at a loading speed of no more than $200 \mathrm{~N} / \mathrm{s}$, each load is $20 \mathrm{kN}$, and each load is added to the first-level load for several minutes. Crack observation and mapping are performed, and the time when the load is added to an integer multiple tonnage. When approaching the ultimate load, continue to load slowly until failure. 


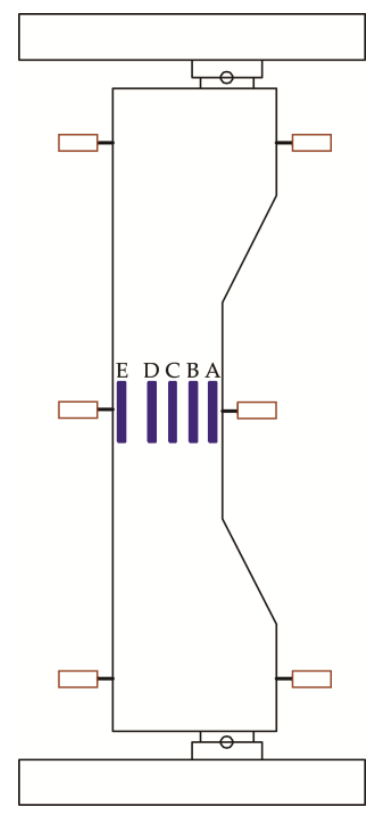

Figure 5. Distribution Diagram of Stain Gauges and Displacement Meters.

\subsection{Analysis of Test Results}

(1) Analysis of Member Deformation Deflection

In order to study the deformation law of bending members with different corrosion degrees as the load increases, the load-deflection curves of components with different corrosion degrees can be drawn to explain intuitively. The load-deflection curves of the test pieces with different specifications under different corrosion conditions are extracted as shown in the Figure 6.

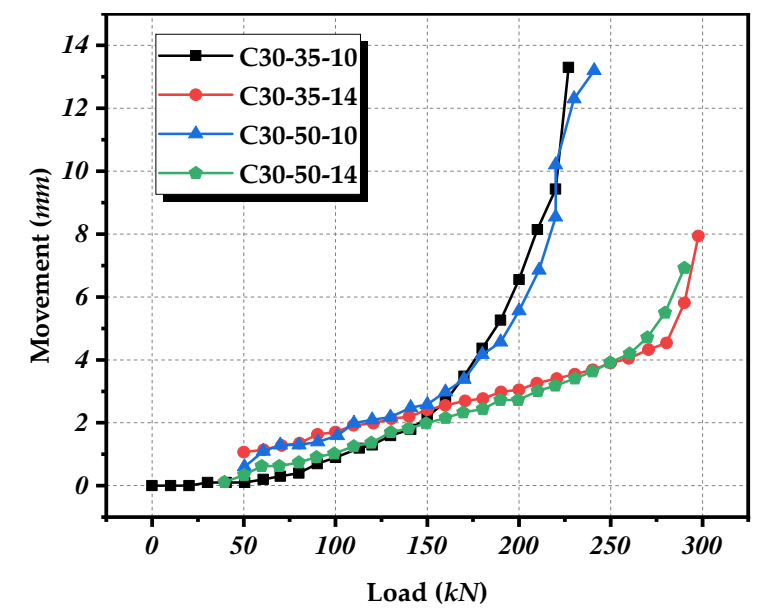

(a) Standard Test Pieces

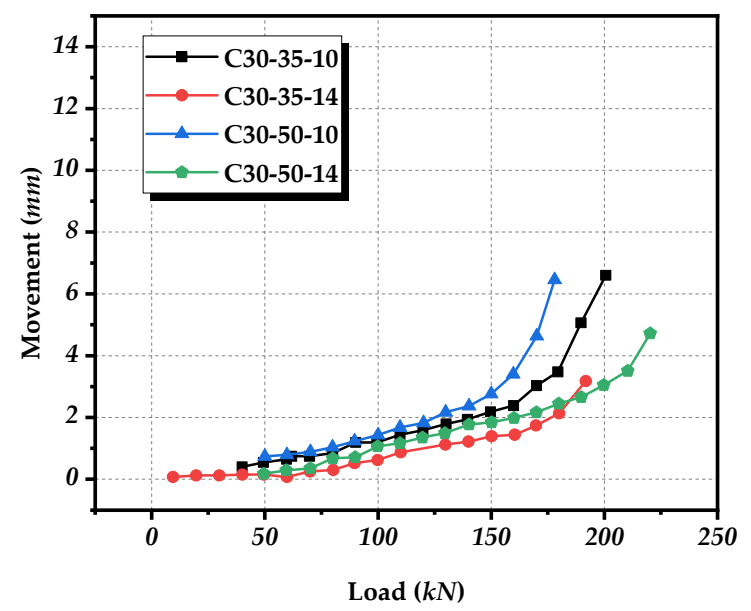

(b) Test Pieces with 8-day Corrosion (1-6)

Figure 6. Load-deflection curves with different accelerated corrosion time.

According to the analysis of the figures above, when all test pieces are loaded near the ultimate load, the deflection will suddenly increase, which is mainly because the failure mode adopted in this test is large eccentricity failure, that is, the test pieces are damaged due to the yield of steel bars. When the steel rebar yields, there will be large tensile deformation, which will cause the sudden change of the deflection of the member. Besides, the deflection of the main tensile rebar test piece with small diameter is relatively large when it is damaged. With the increase of corrosion ratio, the deflection of the 
test piece becomes smaller when it is damaged, which makes the ductility of the compression-bending member smaller and makes the possibility of its brittle failure increase. This indicates that the steel bar has reached the yield, and the load corresponding to the steel bar yield decreases with the influence of corrosion.

(2) Analysis of Overall Bearing Capacity of the Structure

For the overall analysis of the test pieces, based on the initial cracking load and the ultimate load of the test pieces obtained in the compression-bending test, the test data of the test pieces are shown in Figures 7-9. Three sets of tests are conducted for each test piece, so the data presented is the average value of the data obtained from the three sets of tests. Among all the test pieces, the data of some specific test pieces is totally inconsistent with the test rules, especially the cracking load. Due to the construction technology, the internal concrete tamping degree and the errors of manual observation and record, there are some errors in the results, and such values are not taken into account.

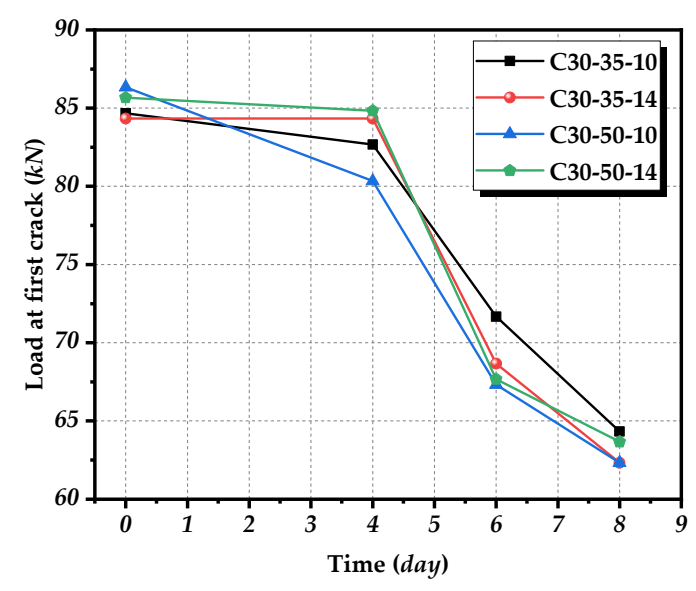

Figure 7. Test Results of Cracking Load of C30 Concrete under Different Corrosion Degree. Conditions.

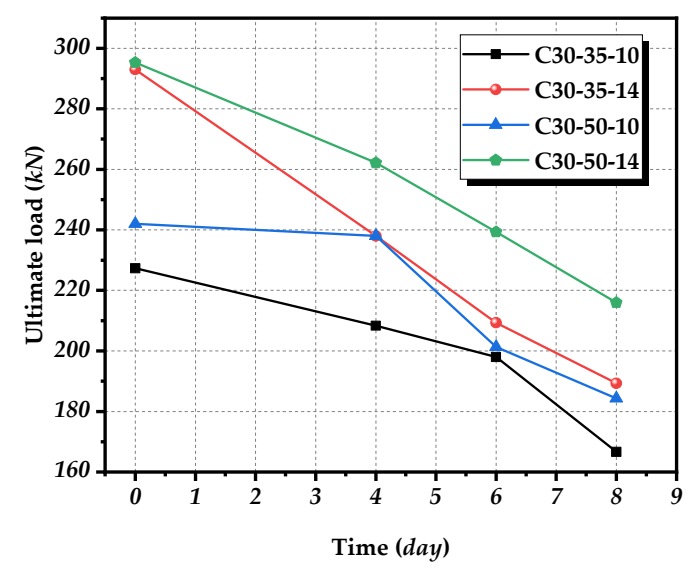

Figure 8. Test Results of Ultimate Load of C30 Concrete under Different Corrosion Degree Conditions.

Based on the data analysis of the test results in Figures 7-9, it can be shown that: With the deepening of the corrosion degree of the steel bars, the bearing capacity of the members decreases continuously. The average ultimate load of C30-35-10 group test pieces is $227.33 \mathrm{kN}$ under non-corrosion condition, and the ultimate bearing capacity of C30-35-10 group test pieces is only $166.67 \mathrm{kN}$ under accelerated corrosion condition for 8 days, with a decrease by more than $26.63 \%$. At the same time, it can be clearly found that the bearing capacity decline under corrosion condition for 4 days is significantly greater than that in the later period. The ultimate bearing capacity of C30-35-14 group test pieces decreases by $21.05 \%$ after four days of accelerated corrosion, decreased by $28.56 \%$ after six days of accelerated corrosion compared with that of non-corroded test pieces, and $35.38 \%$ after eight days of accelerated 
corrosion. According to the analysis of the causes, with the increase of days of accelerated galvanic corrosion, the corrosion degree of the steel bars increases gradually, the effective section and strength of steel bars will decrease gradually, due to which the bearing capacity of the steel bars will also decrease continuously. This process conforms to the rule that the bearing capacity of the reinforced concrete structure will gradually change with the corrosion of the steel bars.

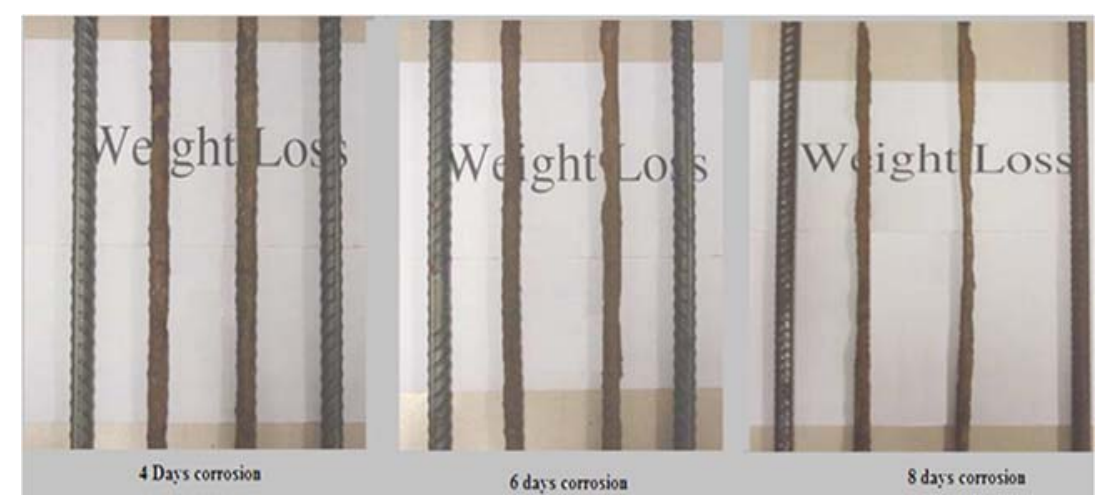

Figure 9. Corrosion effect of steel bars.

The cracking load also decreases with the increase of corrosion ratio. The initial cracking load of the members not under galvanic corrosion is about $80 \mathrm{kN}$; for the members with relatively low corrosion ratio, the initial cracking load is also about $80 \mathrm{kN}$; while the cracking load of the members with large corrosion ratio decreases obviously, which is 60-65 kN. Taking C30-35-10 group test pieces as an example, the cracking load is $84.67 \mathrm{kN}$ under non-corrosion condition, $82.67 \mathrm{kN}$ under corrosion condition for 4 days, and decreases to $71.67 \mathrm{kN}$ under the corrosion condition for 6 days, while the cracking load is only $64.33 \mathrm{kN}$ under the corrosion condition for 8 days. This is mainly due to cracks in the concrete surrounding the reinforcement due to the expansion of the reinforcement, which reduces the cracking load.

\subsection{Compare with Existing Research Results}

In previous studies, Yuan et al. [48] used the artificial climate accelerating corrosion method to study the failure form, ductility, bearing capacity and structural properties degradation mechanism of corroded reinforced concrete flexural members with different eccentricities, as well as the load-deflection relationship comparison of the large and small bias components with different corrosion degrees. The research shows that the specimen undergoes three stages under load: The rising stage before crack formation; the crack formation to the failure stage of the specimen; and the falling stage. The ductility of reinforced concrete members decreases after corrosion. After the tensile reinforcement reaches yield, the concrete in compression zone quickly reaches the ultimate compressive strain, the ductility of corroded member is reduced, and the brittleness is significantly increased.

It can be seen from Figure 6 that the variation of this curve is consistent with the curve of accelerated corrosion method under artificial climate. At the same time, as the diameter of rebar increases, the load required for the curve to appear at a turning point has increased, mainly due to the yield stress of tensile reinforcement increases with diameter.

Fan et al. [49] used the 'replacement member' test method to conduct a flexural bearing capacity test on reinforced concrete members working in a chloride medium environment for a long time. Combined with the test, the mechanical properties of reinforced concrete member under load are compared before and after corrosion. After being corroded by chlorides, the reinforced concrete bending member is under load, and the internal stress effect of concrete expansion caused by corrosion causes the cracking load Pcr of the member to increase. However, if the concrete strength and bonding strength between rebar and concrete are reduced more after corrosion, the cracking load $P c r$ of reinforced concrete will be reduced after corrosion. 
In this paper, electrochemical corrosion is used to test corroded rebar of different diameters, and it is found that the components which do not participate in the energized corrosion increases as the corrosion rate of rebar increases. At the same time, it can be clearly seen from Figure 8 that the reduction in bearing capacity after four days of corrosion is significantly greater than the latter.

\section{Bond Performance between Corroded Steel Rebars and Concrete}

\subsection{Bond-Slip Pull-Out Test of Steel Rebars and Concrete}

The bond performance between steel bars and concrete is affected by various factors, and the interaction between these factors is extremely complex. There are various ways and methods to test and study the bond performance between steel bars and concrete, while they can be classified into three main categories: (1) Direct pull test; (2) simply supported beam or cantilever beam test; (3) local bond-slip test. For the first test method, which is the direct pull test method, the test pieces are easy to fabricate, it is simple to operate and the test results are easy to analyze; comprehensively considering all kinds of factors, such as test loading instrument, test instrument and the test piece fabrication standard, the direct pull test method is adopted for this test.

(1) Fabrication of Test Pieces

For the main reinforcement, the length of $420 \mathrm{~mm}$ is adopted for testing and measuring the slip value of the free end; as for the stirrups, the rectangular closed frame form is adopted, and the spacing is different based on different steel bars. In order to avoid corrosion, the stirrups and the main reinforcement are separated. The anchorage length is chosen to be 4 times of the diameter of the steel rebar, mainly to prevent the steel rebar from yielding under the action of the pull-out load. The specific sizes of the test pieces are as shown in Figure 10. The test piece numbers are C30-10 and C30-14, respectively.
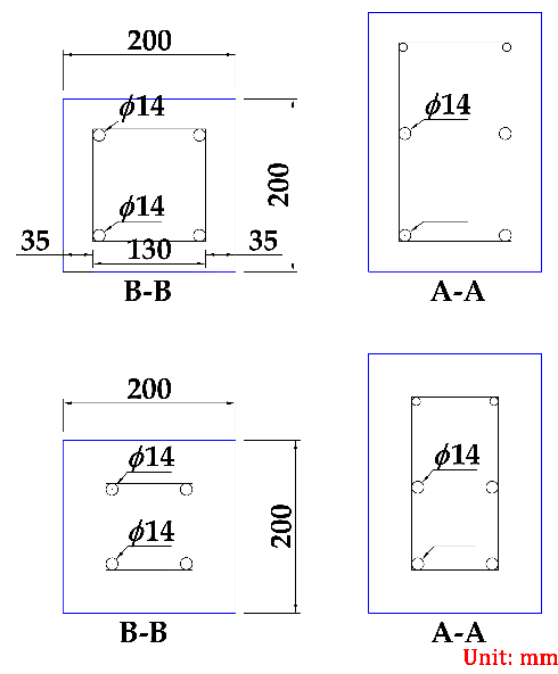

Figure 10. Pull-out Member Section Size and Steel Rebar Distribution Diagram.

(2) Test Methods

The loading equipment used in this uniaxial pull-out test is $300 \mathrm{kN}$ microcomputer controlled universal testing machine, and the testing equipment is KB-150 concrete pullout tester. In order to obtain more accurate test data, KB-150 concrete pull-out tester is especially used to test the bond strength between steel bars and concrete. This test instrument not only meets the standard for mechanical performance test of ordinary concrete, but also meets the regulation for test of hydraulic concrete. The test instrument is as shown in Figure 11. 


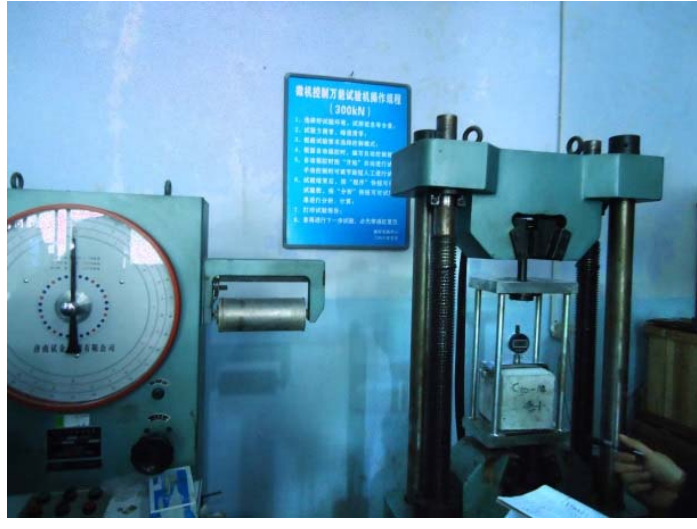

(a)

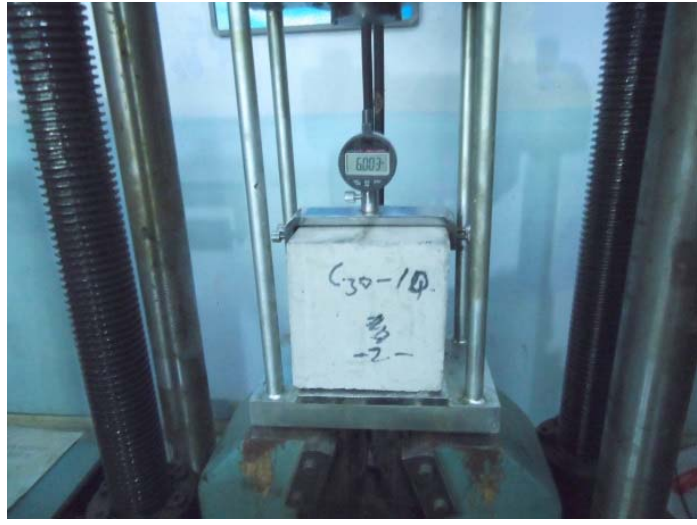

(b)

Figure 11. Uniaxial Pull-out Test Loading and Test Equipment. (a): Overall structure drawing of pull test device; (b): Drawing test device details.

\subsection{Analysis of Test Results}

The pulling load of the test piece is continuously increasing, the bonding performance of the concrete and the reinforcing steel shear is damaged, and the concrete between the ribs is continuously compressed until the part of the concrete is crushed, so that some of the reinforcing steel is pulled out. According to the test, the load value of each test piece with certain pull-out displacement is obtained, and the uniaxial pull-out load displacement curves of each group of test pieces are obtained as shown in the Figures 12 and 13.

Uniaxial pull-out test mode is adopted for this test, assuming that the bond stress coefficient of the contact surface between steel rebar and concrete is uniformly distributed in unit area, and the formula for calculating the bond strength can be assumed as:

$$
\tau=\frac{P}{L \times a} \times 10^{-3}
$$

where $\tau$ is the bond stress (MPa); $\mathrm{P}$ is the drawing load $(\mathrm{kN}) ; \mathrm{L}$ is the embedded length of steel bar $(\mathrm{mm})$; $\mathrm{a}$ is the circumference of steel bar cross section $(\mathrm{mm})$.

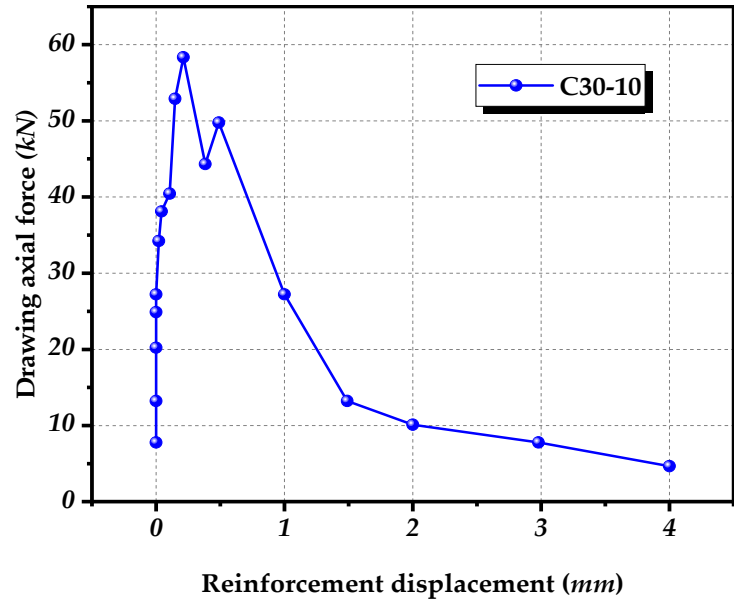

(a)

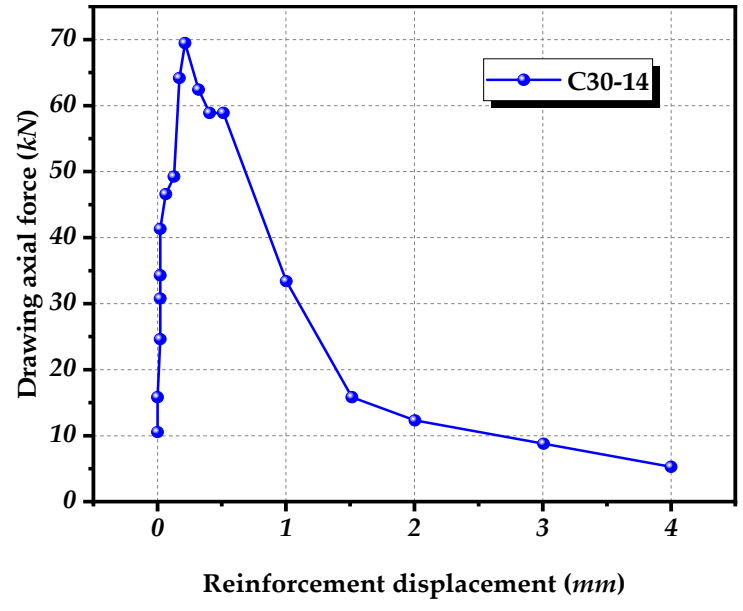

(b)

Figure 12. C30 Standard Test Piece Pull-out Load Displacement Diagram. (a): C30-10; (b): c30-14. 


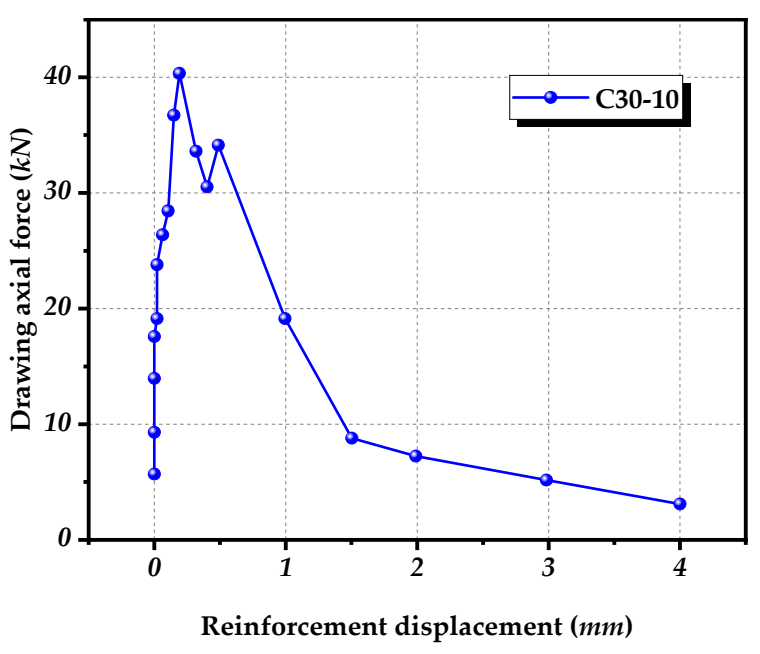

(a)

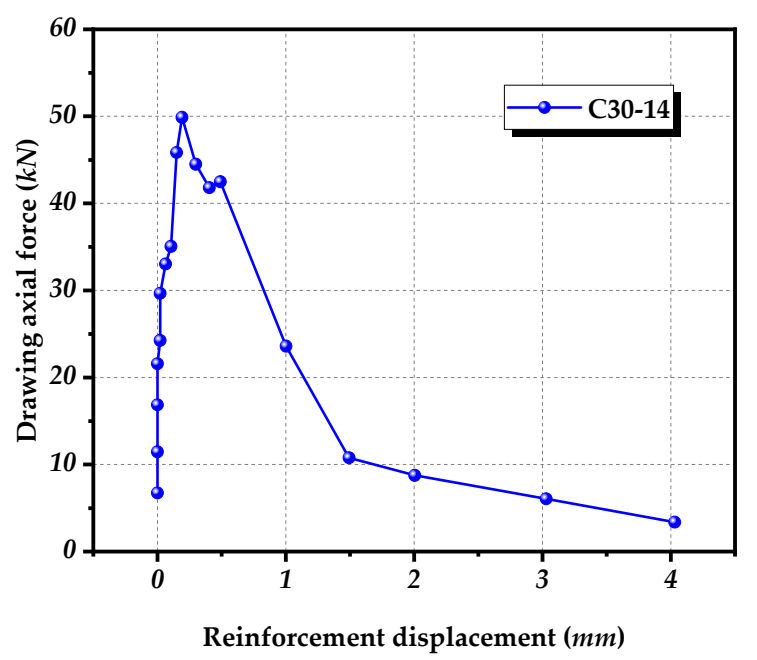

(b)

Figure 13. C30 8-day Corrided Test Piece Pull-out Load Displacement Diagram. (a): C30-10; (b): C30-14.

The obtained maximum pull-out axial force of the uniaxial pull-out test pieces and the corresponding corrosion degree are listed in Figures 12 and 13, respectively. The bond strength results calculated by formula (2) are as shown in Figures 14 and 15.

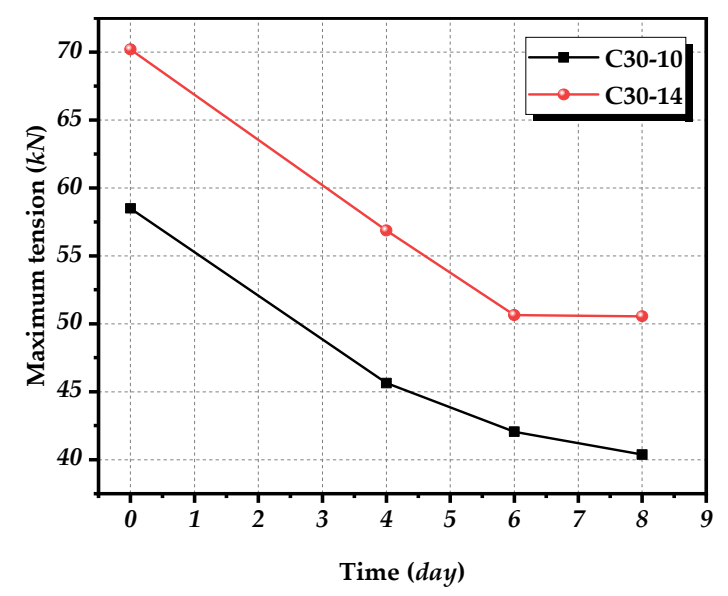

Figure 14. Bearing Capacity of Pull-out Test Pieces.

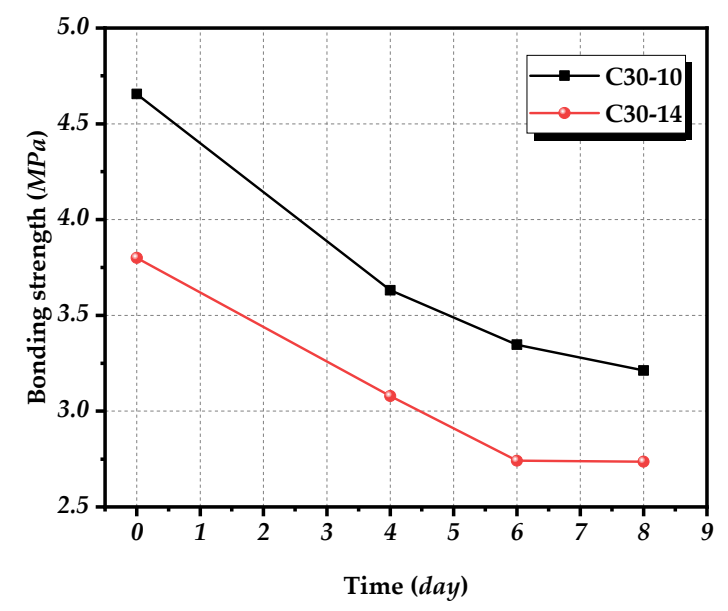

Figure 15. Bond Strength of Pull-out Test Pieces. 
According to the analysis of Figures 14 and 15, the general trend of the pull strength before and after corrosion is very similar. When the pull-out force increases to the maximum value, the pull-out force will decrease rapidly as the ultimate bond strength is reached. In the descending phase of most test pieces after the maximum load is reached, there will be a rebound of force, and this is the process in which the concrete between the ribs of the steel bars is thoroughly crushed. One of the factors affecting the bond performance between steel rebar and concrete is the bond area of the steel rebar, the size of which is determined by the circumference of the section, while the size of the section is determined by the tensile force of the steel rebar. The test pieces with larger diameter of steel rebar can bear larger axial tensile force, but its bond strength is smaller. The bond stress will decrease with larger area of the steel rebar and larger relative bond area. Taking the standard test pieces as an example, the bond strength of C30-10 group test pieces is $4.66 \mathrm{Mpa}$, while that of C30-14 group test pieces is 3.80 MPa. The rule is also true for corroded test pieces. After eight days of accelerated corrosion, the bond strength of C30-10 group test pieces is only $3.21 \mathrm{MPa}$, decreasing by $31.12 \%$, while the bond strength of C30-14 group test pieces decreases by $27.89 \%$, which is only $2.74 \mathrm{MPa}$. Corrosion of steel rebar is the main factor affecting corrosion of concrete and steel rebar. The ultimate pull-out force is decreasing with the increase of the corrosion ratio. The ultimate pull-out bearing capacity of C30-10 group test pieces decreases by $30.99 \%$ after eight days of constant current accelerated corrosion, while the bond strength decreases by $22 \%$ after four days of accelerated corrosion. Comparing with other groups of test pieces, it is not difficult to find that the decreasing rate of the ultimate pull-out bearing capacity is decreasing with the increase of corrosion degree.

\subsection{Compare with Existing Research Results}

Yuan et al. mixed rebar with chloride and exposed them to natural climates indoor and outdoor to approximate the actual effect of corrosion. From the results, it can be seen that the bond-slip curve of uncorroded reinforced concrete is composed of three parts, rising, approximate horizontal and falling. While the corroded reinforced concrete bond-slip curve consists of only two parts, rising and falling, and the gradient of corrosion decline curve increases with the degree of corrosion.

It can be seen from Figure 13 that after corrosion accelerated by current, the reinforced concrete bond-slip curve is also composed of only the rising and falling sections, and the test results are similar to the corrosion effect under natural conditions.

In addition, comparing the bonding strength under different rebar diameters, it is clear that as the rebar diameter decreases, the peak value of the curve also decreases. This is mainly because the bonding area of the contact between rebar and concrete is reduced as the diameter of rebar is reduced. This rule is also consistent with the experimental results made by Zhao et al. [50].

Since the main source of bonding strength between deformed rebar and concrete is the bite force between the deformed rebar rib and concrete, this is a more important influencing factor: As the amount of rebar corrosion increases, the area of ribs and concrete becomes smaller and smaller, which leads to the decline of bonding strength.

\section{Numerical Analysis of Performance Degradation of Corroded Reinforced Concrete Lining}

Through the bending tests of corroded reinforced concrete members described in Section 2, the mechanism governing structural durability loss of reinforced concrete materials degraded by corrosion has been roughly understood. When the mechanism found from the tests are applied to the actual tunnel lining structures, the numerical simulation code can be used to simulate and analyze the mechanical properties of the tunnel support system degraded by rebar corrosion. In this research, by referring to Dong et al 's [51] traditional pull-out tests to measure the bond-slip behaviors of reinforced concrete structures, and based on the mechanism behind material strength loss found from pull-out tests described in Section 3 to investigate the bond-slip behavior of reinforced concrete structures, the traditional formula for bond-slip model of lining structures is obtained. Based on the existing experimental results, an ANSYS-based 3-D finite element model for tunnel reinforced 
concrete lining structure was established. By choosing the appropriate material constitutive model, and by simulating the bond-slip effect between rebars and concrete through spring structural element, the change of overall bearing capacity of the structures caused by material degradation due to corroded rebars under different burial depth was analyzed.

\subsection{Structural Elements Determination and Model Establishment}

At present, there are three main modeling methods for reinforced concrete structures: separate modeling, modular modeling, and integral modeling. Sinceedi it is the bond-slip effect between rebars and concrete that should be simulated, only separate modeling is adopted to simulate the relative slip between rebars and concrete by setting appropriate parameters of connecting elements. The concrete element used in this computation is solid65, and link8 element is used to simulate the rebars. Link10 bar element (set to be subject to compression only) is used to simulate the effect of surrounding rock on the main structure. Combin39 of 0 length is selected as the connecting element. This element can help the software to compute the sliding direction and the sliding distance from the corresponding curves, and finally obtain the stiffness coefficient of the connecting spring. It can effectively simulate the degradation of bonding performance and the change of bond stiffness of reinforced concrete structures. In order to save computation time and space and considering the actual mechanical state of the tunnel and the loading conditions in the model, the tunnel model is established as a half-edge model in this computation. The specific modeling is shown in Figure 16.

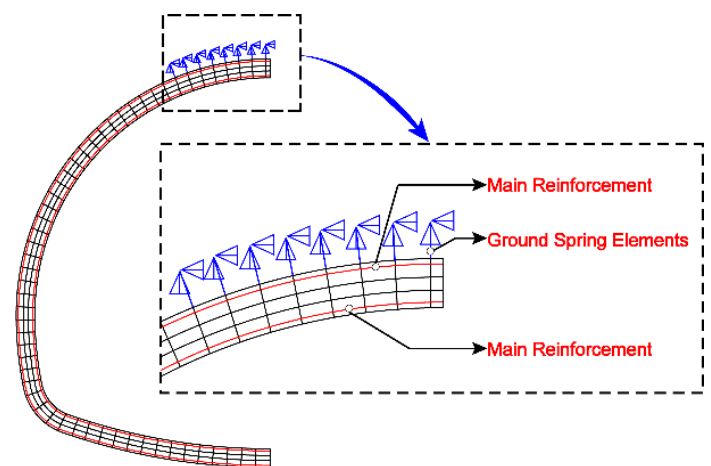

(a)

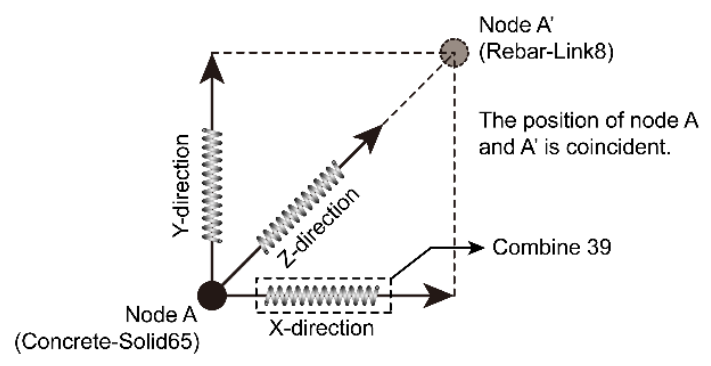

(b)

Figure 16. ANSYS numerical model: (a) RCS model with Ground Spring Elements; (b) Bond-Slip Spring Element. The two legends above are all front views of the model.

\subsection{Setting Material Parameters and Working Conditions for Computation}

In this computation, SOLID65 element is defined by W-W parametric strength model: the shear transfer coefficient during the opening of concrete crack is set to 0.7 , the shear transfer coefficient during closing of crack is set to 1.0, the uniaxial tensile strength is set to 2.01 and the uniaxial compressive strength is set to 31.4. As well, concrete failure under multiaxial stress is simulated by setting the ultimate strength of concrete under tension and compression.

The representation of the bonding performance between rebars and concrete is the key to the utilization of finite element simulation in analyzing the bonding performance of corroded reinforced concrete, which is expressed by the relationship between bond stress and local slip. The local bond slip model is as follows:

$$
\begin{aligned}
& \tau_{c}=\beta\left(61.5 S-693 S^{2} 3140 S^{3}-4780 S^{4}\right) f_{t s} \sqrt{c / d}
\end{aligned}
$$

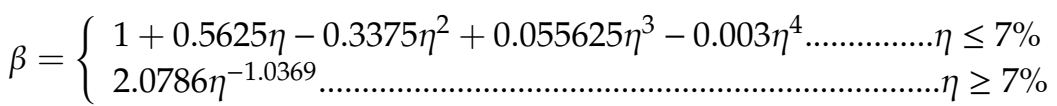

where $\tau_{c}$ is the bond stress (MPa); $\beta$ is the coefficient of bond strength reduction; $S$ is the slip (mm); $f_{t s}$ is the splitting strength of concrete (MPa), $f_{t s}=0.19 f_{\mathcal{c}}^{0.75}, f_{c u}$ is axial compressive strength (MPa); 
$c$ is the cover thickness (MPa); $d$ is the diameter of reinforcing bar (mm); $\eta$ is the loss rate of steel bar section [52].

Based on the variation of bond strength between rebars and concrete with the corrosion degree of rebars obtained from bond-slip pull-out tests of reinforced concrete described in Section 3, the bond strength reduction factor, can be selected as shown in Figure 17.

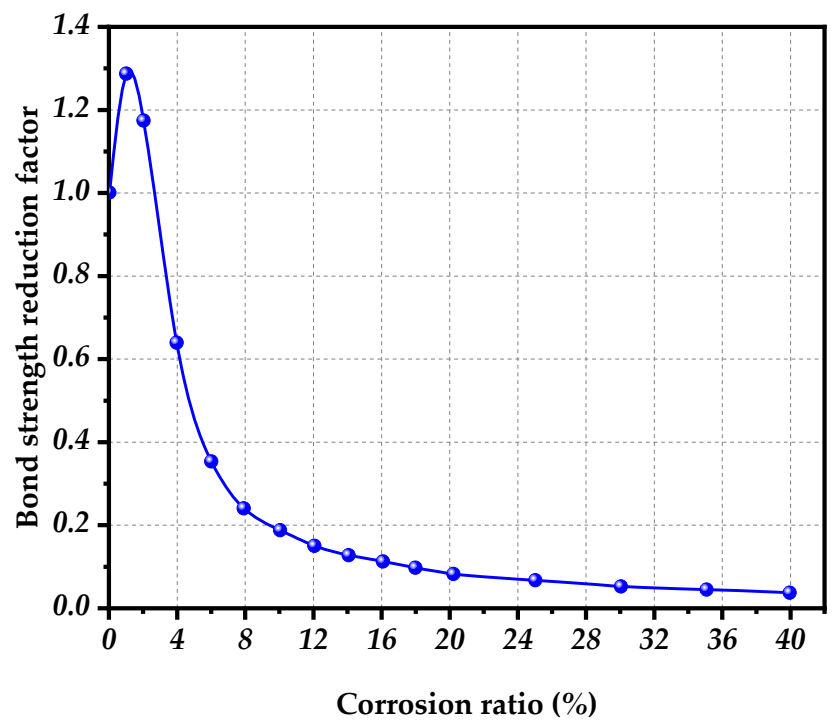

Figure 17. Variation of $\beta$ with corrosion ratio.

With the general situations of actual engineering taken into account, the selection of material parameters is shown in Table 3.

Table 3. Parameters of Surrounding Rock and Supporting Material.

\begin{tabular}{cccccc}
\hline Materials & $\begin{array}{c}\text { Modulus of } \\
\text { Elasticity (GPa) }\end{array}$ & Poisson Ratio & $\begin{array}{c}\text { Unit Weight } \\
\left(\mathbf{k N} / \mathbf{m}^{3}\right)\end{array}$ & $\begin{array}{c}\text { Cohesion } \\
(\mathbf{M P a})\end{array}$ & $\begin{array}{c}\text { Internal } \\
\text { Friction Angle } \\
\left({ }^{\circ}\right)\end{array}$ \\
\hline $\begin{array}{c}\text { V-Class } \\
\text { Surrounding rock }\end{array}$ & 1.5 & 0.4 & 18 & 0.1 & 25 \\
\hline Secondary lining & 30 & 0.2 & 23 & - & - \\
\hline Steel bar & 210 & 0.3 & 78 & - & - \\
\hline
\end{tabular}

With the actual engineering and research needs taken into account, the representative burial depth of $15 \mathrm{~m}$ and $50 \mathrm{~m}$ is selected in this computation. Then, the surrounding rock pressures under the two working conditions are computed by referring to the Highway Tunnel Design Code, JTG D70-2-2014. Based on the experimental results described in Section 3 and the research results from other scholars at home and abroad, according to Figure 17, the corrosion ratios of rebars selected for this computation includes $0 \%, 1.5 \%, 3 \%, 7 \%, 15 \%$ and $30 \%$.

\subsection{Analysis of Computation Results}

(1) Deformation of Tunnel Lining Structure under Different Rebar Corrosion Conditions.

Under different burial depths, with the increase of rebar corrosion, the lining deformation aggravates, the vault of lining structure will settle to a certain extent. The extracted variations of settlement of the vault of lining structure with the rebar corrosion ratio are shown in Figure 18. 


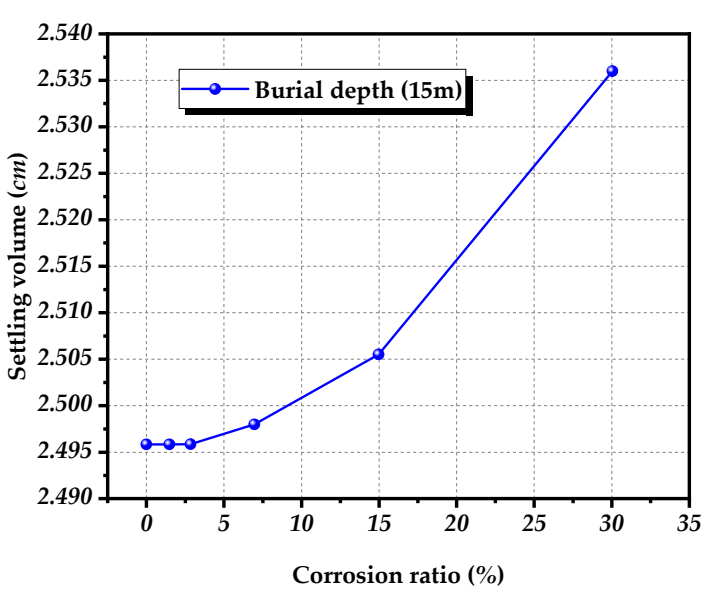

(a)

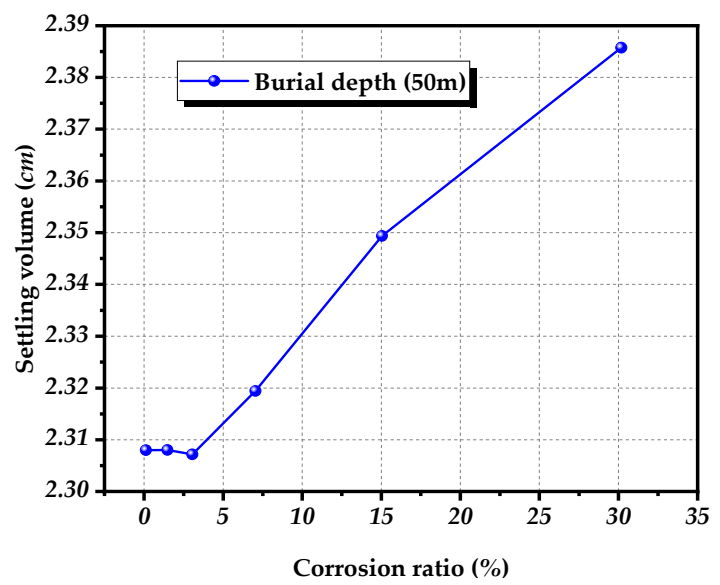

(b)

Figure 18. Variation of vault settlement with corrosion ratio under different depth: (a) buried depth $15 \mathrm{~m}$; (b) buried depth $50 \mathrm{~m}$.

As can be seen from Figure 18, the settlement of vault increases with the increase of steel corrosion under different burial depth. Compared with the scenario of 50-metre burial depth, the settlement of vault is larger in the scenario of 15-metre burial depth. The settlement of the vault in the scenario of 15 -metre burial depth is $2.496 \mathrm{~cm}$ when no corrosion occurs. When the corrosion degree reaches $30 \%$, the displacement of the vault reaches $2.536 \mathrm{~cm}$, showing an increase by $1.6 \%$, while the displacement of the vault in the scenario of 50-metre burial depth increases by $3.4 \%$. Generally speaking, it can be seen that the settlement of the vault of lining structure caused by the corrosion of rebars did increase, but by a small margin.

(2) Concrete Cracking of Tunnel Lining Structures under Different Corrosion Conditions of Rebars.

In order to study the ultimate stress condition of the reinforced concrete when cracking occurs to it under different corrosion conditions, the stress-strain curves of inner concrete in three scenarios were extracted and compared: without corrosion, with a corrosion ratio of $7 \%$ and with a corrosion ratio of 30\%, as shown in Figure 19.

By analyzing the stress-strain curves of concrete shown in Figure 19, it can be found that the concrete cracking stress can be determined to be the stress value where there is a big jump in the curve. After comparison among the curves, it can be found that the concrete cracking stress under different corrosion ratios is all $1800 \mathrm{KPa}$ at which the lining structure cracks, during which the cracking stress has no obvious change. Figure 19 shows the crack damage evolution process of concrete by monitoring the change of stress state with time in the numerical calculation process, and the peak value represents the ultimate tensile strength. Since the ultimate tensile strength is the material characteristic parameter of concrete itself, the corrosion rate of reinforcement does not change this parameter, so the corrosion rate does not change the initial crack strength and cracking state of concrete. However, it will affect the distribution range and development trend of cracks, which will lead to the deterioration of the whole lining structure. The corrosion rate will affect the bearing capacity and safety greatly.

(3) Relative Slip Between Rebar and Concrete under Different Corrosion Conditions of Reinforced Concrete.

With the increasing corrosion of rebars, the relative dislocation between concrete and rebars in reinforced concrete lining structure will eventually lead to structural failure, which is also the focus of this paper. The relative slips of concrete and rebar at a series of key points (selection of key points shown in Figure 20) along the tunnel circumference are extracted and plotted, to analyze and study the slip state of various parts. The results are shown in Figure 21. 


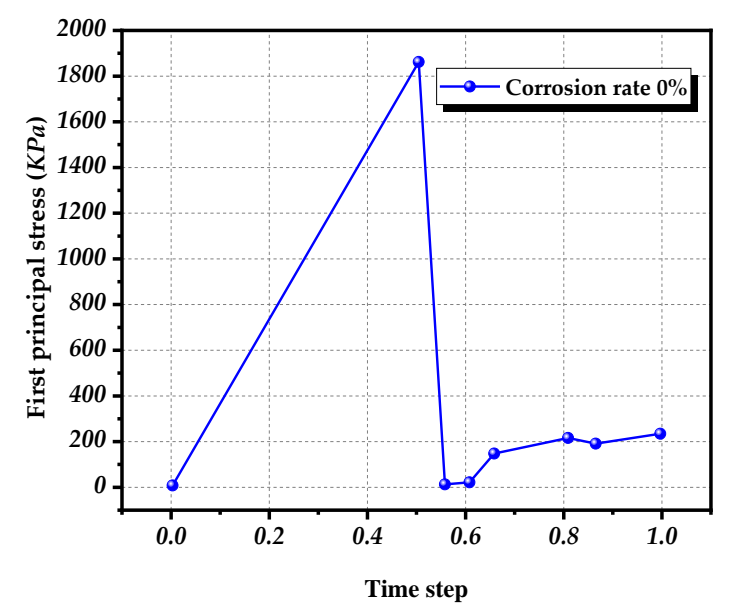

(a)

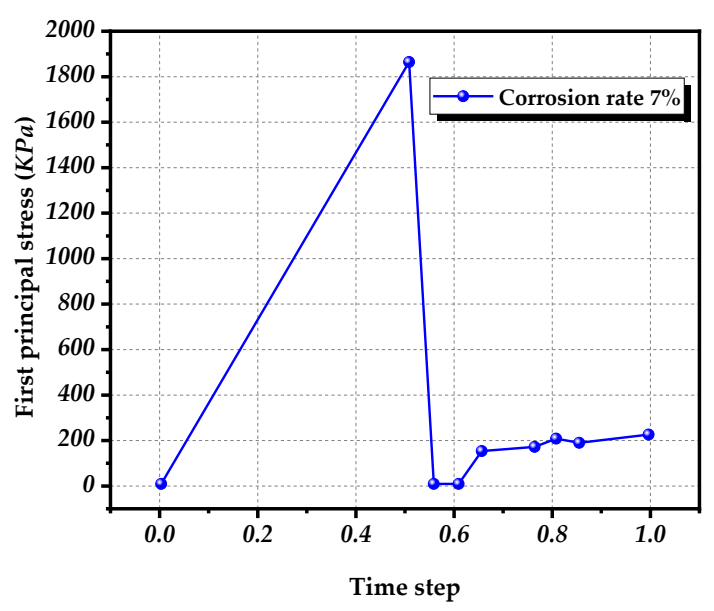

(b)

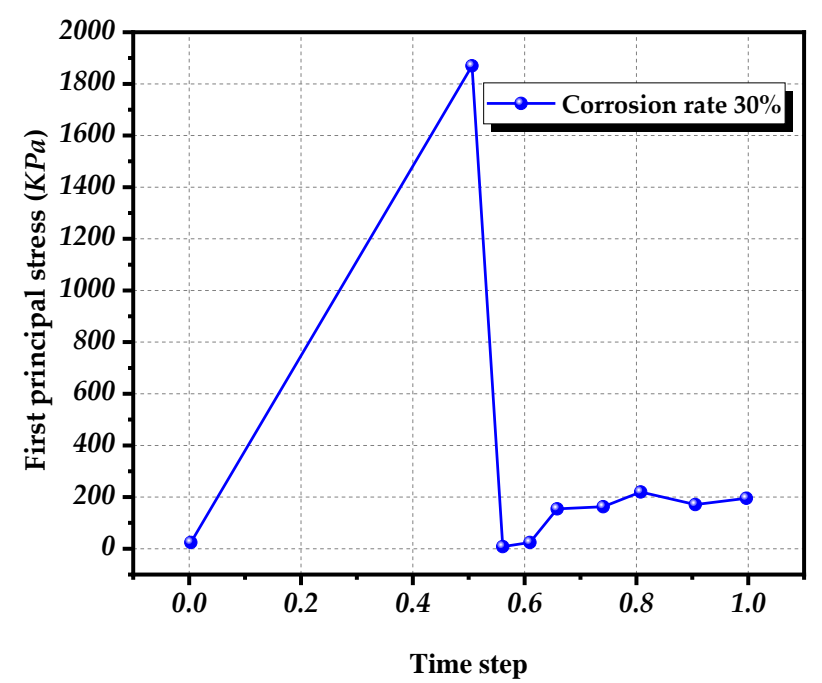

(c)

Figure 19. Stress-time step curve of concrete structure: (a) Uncorroded; (b) 7\% Corroded; (c) 30\% Corroded (time step means calculation step).

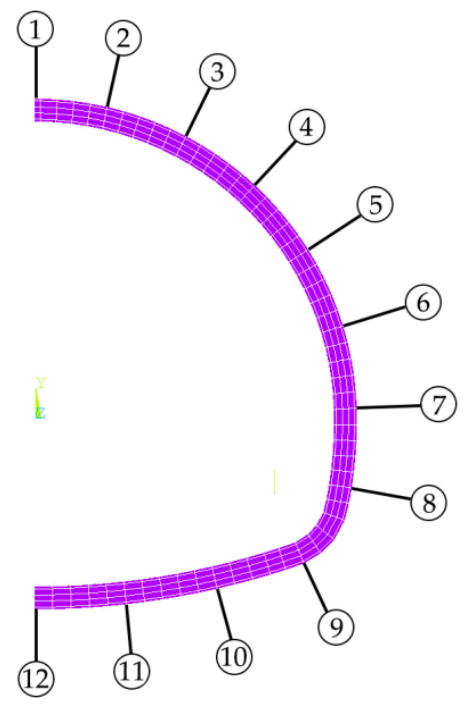

Figure 20. Schematic diagram showing characteristic section selection. 


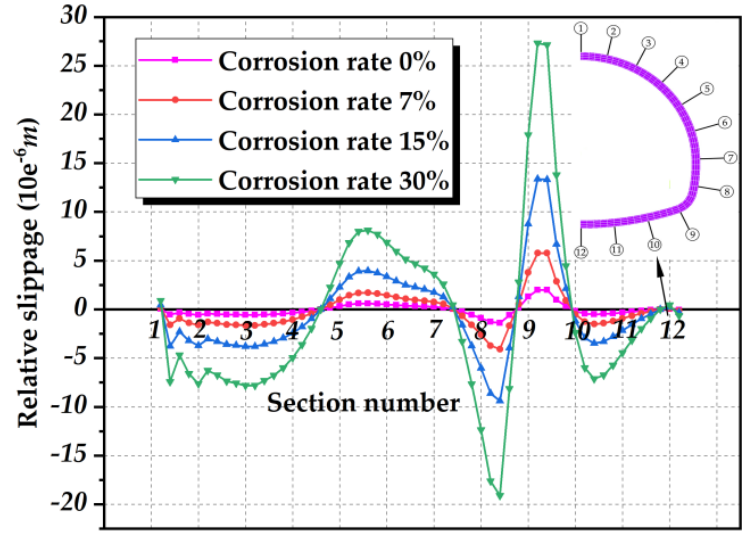

(a)

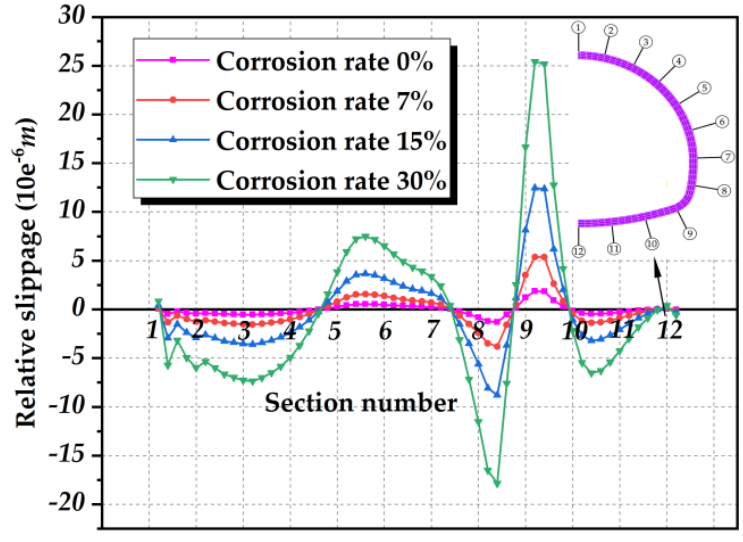

(b)

Figure 21. Relative slips for characteristic section under different corrosion ratios: (a) $15 \mathrm{~m}$ burial depth; (b) $50 \mathrm{~m}$ burial depth.

Analysis of the curves in Figure 21 shows that:

Under the same burial depth, with the increasing corrosion ratio of rebars, the relative slip between rebars and concrete increases continuously, and the change range is larger, up to 10 times that under the condition of no corrosion. Under the two burial depths, with the change of corrosion ratio of rebars, the change patterns of relative slips between rebar and concrete in lining structure are basically consistent. The maximum slip occurs at the footing of the tunnel lining, mainly because the lining at the wall footing bears greater concentrated stress.

(4) Overall Safety Performance of Tunnel Lining Structures under Different Corrosion Conditions of Reinforced Concrete.

To evaluate the overall safety of tunnel lining structure under different reinforcement corrosion conditions, the bending moments and axial forces of twelve key sections of tunnel lining under different corrosion ratios and burial depths are extracted respectively for this computation. The safety factors of different sections of tunnel lining are computed by referring to JTG D70-2-2014, which are used to analyze the safety performance of the whole structure. The selection of characteristic cross sections is shown in Figure 20.

According to the above method, the safety factors of tunnel lining sections under different burial depths and corrosion conditions can be extracted and obtained through computation. The safety factors of the most dangerous sections under different working conditions are analyzed, with the results shown in Table 4 and Figure 22.

Table 4. Table of Most Dangerous Safety Factor for Each Working Condition.

\begin{tabular}{ccccccc}
\hline \multicolumn{7}{c}{ Calculate Results } \\
\hline Condition & $15 \mathrm{~m}(0 \%)$ & $15 \mathrm{~m}(1.5 \%)$ & $15 \mathrm{~m}(3.0 \%)$ & $15 \mathrm{~m}(7.0 \%)$ & $15 \mathrm{~m}(15.0 \%)$ & $15 \mathrm{~m}(30.0 \%)$ \\
Safety factor & 2.741 & 2.612 & 2.475 & 2.305 & 1.804 & 1.442 \\
Section Number & 1 & 9 & 8 & 10 & 8 & 9 \\
Condition & $50 \mathrm{~m}(0 \%)$ & $50 \mathrm{~m}(1.5 \%)$ & $50 \mathrm{~m}(3.0 \%)$ & $50 \mathrm{~m}(7.0 \%)$ & $50 \mathrm{~m}(15.0 \%)$ & $50 \mathrm{~m}(30.0 \%)$ \\
Safety factor & 2.814 & 2.671 & 2.315 & 2.258 & 1.847 & 1.539 \\
Section Number & 8 & 9 & 8 & 9 & 9 & 9 \\
\hline
\end{tabular}

It can be seen from Table 4 and Figure 22 that under different burial depths, the safety factor values of dangerous sections show small difference under different corrosion ratios of rebars, and with the increase of the corrosion degree of reinforcing bars, the change patterns of the structural safety performance is the same. Compared with Duan Shaoli's research on the safety factor of tunnel lining structure under the condition of uncorroded steel bars, it can be ground, and the safety factor of the lining tunnel structure after corrosion of the steel bars is obviously reduced. Under the same 
burial depth, when the corrosion ratio exceeds $7 \%$, the safety factor of the structure decreases greatly. When the corrosion ratio reaches $30 \%$, the safety factors of the sections cannot meet the requirements of the Code $(K=1.7)$, which roughly show the loss of safety of the lining structure. Therefore, for the sake of structural safety, the allowable corrosion of the tunnel reinforced concrete lining structure should be less than $30 \%$. By analyzing the position of the most dangerous sections, it can be concluded that the wall footing of the lining structure is the most dangerous position and needs much attention.

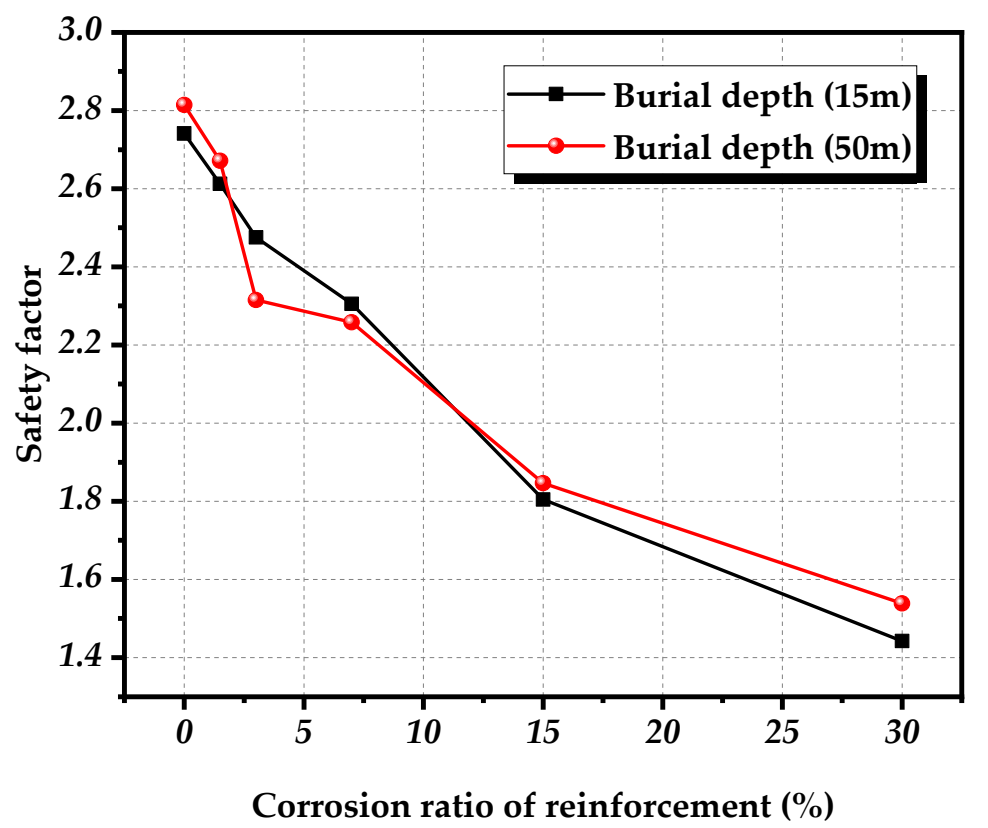

Figure 22. Safety factors of the most dangerous sections under various working conditions.

\section{Conclusions}

This paper takes the Yanlangshan Tunnel of Zhuhai Airport Expressway as the engineering background to study the influence of rebar corrosion on tunnel lining structure. Based on structural performance 'bending-uniaxial pullout' test, combined with finite element numerical simulation analysis, the general laws affecting the durability and bearing capacity of reinforced concrete lining structure are obtained. The main research contents and achievements are as follows:

(1) From the experimental study of the bending tests of corroded reinforced concrete members, it can be found that with the increase of corrosion ratio, the deflections of the test pieces become smaller when they are damaged, and the ductility of the bending members becomes smaller and the possibility of brittle failure increases. At the same time, the thickness of the concrete cover has a certain effect on the deflection. The test pieces with thicker concrete cover have smaller deflection when they are damaged, but the difference is relatively small. At the same time, with the increase of rebar corrosion ratio, the bearing capacity of members decreases, and the cracking load decreases with the increase of corrosion ratio.

One factor that affects the bonding performance of rebar and concrete is the bonding area, the size of which is determined by the perimeter of cross section, and the size of cross section is determined by the tensile force of rebar. The test piece with a larger diameter can bear larger axial tensile force, but the bonding strength is smaller. Due to the larger rebar and bonding area, the bonding stress is reduced. Taking standard parts as an example, the bonding strength of C30-10 group test pieces is $4.66 \mathrm{Mpa}$, while strength of C30-14 group test pieces is $3.80 \mathrm{Mpa}$, and this rule is also the same in corrosion test pieces. After eight days of accelerated corrosion, the bonding strength of C30-10 group test pieces is only $3.21 \mathrm{Mpa}$, a decrease of $31.12 \%$, and strength of C30-14 group test pieces is a decrease of $27.89 \%$, only $2.74 \mathrm{Mpa}$. As the corrosion rate increases, the ultimate drawing force continues to decrease. After eight days of constant current accelerated corrosion, the C30-10 group test pieces' ultimate pull-out 
bearing capacity decreases by $30.99 \%$, and the adhesion drop rate is $22 \%$ after four days of acceleration. Comparing the other groups of test pieces, it is not difficult to find that the decrease in ultimate pull-out bearing capacity decreases continuously as the degree of corrosion increases.

(2) From the pull-out tests of corroded rebar and concrete to investigate their bond-slip behaviors, it can be concluded that the general changing patterns of pull-out strength before and after corrosion are very similar. When the pull-out force increases to the maximum value, the pull-out force will decrease rapidly as the allowable bond strength is reached. One of the factors affecting the bonding behaviors between rebars and concrete is the bonding area of rebars. The test pieces of larger diameter rebars have larger axial pull-out force, but smaller bond strength. Since the surface area of rebars is larger, the relative bond area is larger, so the bond stress decreases. In practical engineering, the bonding performance of the structures can be improved by using rebars of appropriate diameter.

Taking standard parts as an example, the bonding strength of C30-10 group test pieces is $4.66 \mathrm{Mpa}$, while strength of C30-14 group test pieces is $3.80 \mathrm{Mpa}$, and this rule is also the same in corrosion test pieces. After eight days of accelerated corrosion, the bonding strength of C30-10 group test pieces is only $3.21 \mathrm{Mpa}$, a decrease of $31.12 \%$, and strength of C30-14 group test pieces is a decrease of $27.89 \%$, only $2.74 \mathrm{Mpa}$.

(3) The numerical simulation results of tunnel lining reinforced concrete structure are basically consistent with the experimental results. With the aggravation of rebar corrosion, the structural deformation will increase but the extent is small, and the cracking of concrete will hardly be affected. However, the relative slip of rebars and concrete will increase significantly with the increase of corrosion ratio. With the aggravation of structural degradation, the overall safety of tunnel lining structure is greatly affected, and the safety of the lining structure will be basically lost when the final corrosion rate of the steel bars is greater than $30 \%$.

Author Contributions: Z.Z. analyzed the calculation results. R.G. carried out the numerical simulation and wrote the article. H.Z. offered useful suggestions for the preparation and writing of the paper. W.H. processed the data. All authors have read and agreed to the published version of the manuscript.

Funding: The study was supported by the National Key Research and Development Program of China (2016YFC0802202), the General Program of the National Natural Science Foundation of China (51878572) and Sichuan Science and Technology Program (2019YFG0460).

Acknowledgments: We also highly appreciate the contribution of data collection from China Railway 12 Bureau Group Co., LTD. Finally, the authors would like to thank reviewers for useful comments and editors for improving the manuscript.

Conflicts of Interest: The authors declare no conflict of interest.

\section{References}

1. Zhang, H.; Chen, L.; Zhu, Y.; Zhou, Z.; Chen, S. Stress Field Distribution and Deformation Law of Large Deformation Tunnel Excavation in Soft Rock Mass. Appl. Sci. 2019, 9, 865. [CrossRef]

2. Zhu, Y.; Chen, L.; Zhang, H.; Zhou, Z.; Chen, S. Physical and Mechanical Characteristics of Soft Rock Tunnel and the Effect of Excavation on Supporting Structure. Appl. Sci. 2019, 9, 1517. [CrossRef]

3. Zhang, Z.Q.; Zhang, H.; Tan, Y.J.; Yang, H.Y. Natural wind utilization in the vertical shaft of a super-Long highway tunnel and its energy saving effect. Build. Environ. 2018, 145, 140-152. [CrossRef]

4. Zhang, H.; Chen, L.; Chen, S.G.; Sun, J.C.; Yang, J.S. The spatiotemporal distribution law of microseismic events and rockburst characteristics of the deeply buried tunnel group. Energies 2018, 11, 3257. [CrossRef]

5. Yan, J.X. Achievements and Challenges of Tunneling Technology in China over Past 40 Years. Tunn. Constr. 2019, 39, 537-544. [CrossRef]

6. Hong, K. Development and prospects of tunnels and underground works in China in recent two years. Tunn. Constr. 2017, 37, 123-134.

7. He, J.; Gao, B.; Xue, T.; Bai, Y. Consideration on scientific maintenance management of highway tunnel in China. Tunn. Constr. 2018, 38, 51-57.

8. Zhang, Z.Q.; Li, H.Y.; Yang, H.Y.; Wang, B. Failure modes and face instability of shallow tunnels under soft grounds. Int. J. Damage Mech. 2019, 28, 566-589. [CrossRef] 
9. Zhang, Z.; Luo, C.; Zhang, H.; Gong, R. Rockburst Identification Method Based on Energy Storage Limit of Surrounding Rock. Energies. 2020, 13, 343. [CrossRef]

10. Zhang, H.; Zhu, Y.; Chen, L.; Hu, W.; Chen, S. The Prevention and Control Mechanism of Rockburst Hazards and Its Application in the Construction of a Deeply Buried Tunnel. Appl. Sci. 2019, 9, 3629. [CrossRef]

11. Zhang, Z.Q.; Shi, X.Q.; Wang, B.; Li, H.Y. Stability of NATM tunnel faces in soft surrounding rocks. Comput. Geotechnol. 2018, 96, 90-102. [CrossRef]

12. Zhang, Z.Q.; Sun, F.; Chen, B.K. Thermo-mechanical coupled analysis for tunnel lining with circular openings. Tunn. Undergr. Space Technol. 2020, in press. [CrossRef]

13. Yang, X.M.; Wu, T.Y.; Chen, Y.L. Experimental study on the bending performance of corroded reinforced concrete beam. J. Nat. Disasters. 2018, 27, 70-78.

14. Wu, H.; Yao, C.K.; Li, C.H.; Miao, M.; Zhong, Y.J.; Lu, Y.Q.; Liu, T. Review of Application and Innovation of Geotextiles in Geotechnical Engineering. Materials. 2020, 13, 1774. [CrossRef] [PubMed]

15. Qiu, J.L.; Lu, Y.Q.; Lai, J.X.; Zhang, Y.W.; Yang, T.; Wang, K.; Liu, T. Experimental study on the effect of water gushing on loess metro tunnel. Environ. Earth Sci. 2020, 79, 1-15.

16. Liang, Y.N.; Yuan, Y.S. Effects of environmental factors of sulfate attack on deterioration of concrete mechanical behavior. J. China Univ. Min. Technol. 2005, 4, 452-457.

17. Liang, Y.N.; Yuan, Y.S. Constitutive relation of sulfate attacked concrete under uniaxial compression. J. Harbin Inst. Technol. 2008, 41, 532-535.

18. Zhang, W.P.; Shang, D.F.; Gu, X.L. Stress-strain relationship of corroded steel bars. J. Tongji Univ. (Nat. Sci.) 2006, 5, 586-592.

19. Hui, Y.L.; Lin, Z.S.; Li, R. Experimental Study and Analysis on the Property of Corroded Rebar. Ind. Constr. 1997, 6, 11-14.

20. Blomfors, M.; Zandi, K.; Lundgren, K. Engineering bond model for corroded reinforcement. Eng. Struct. 2018, 156, 394-410. [CrossRef]

21. Liu, T.; Weyers, R.W. Modeling the dynamic corrosion process in chloride contaminated concrete structures. Cem. Concr. Res. 1998, 28, 356-379. [CrossRef]

22. Bazant, Z.P. Physical model for steel corrosion in concrete sea structures-theory. Asce J. Struct. Div. 1979, 105, 1137-1154.

23. Zhu, W.; François, R.; Poon, C.S.; Dai, J.G. Influences of corrosion degree and corrosion morphology on the ductility of steel reinforcement. Constr. Build. Mater. 2017, 148, 297-306. [CrossRef]

24. Jin, W.L.; Zhao, Y.X. State-of-the-art on durability of concrete structures. J. Zhejiang Univ. (Eng. Sci.) 2002, 36, 371-380.

25. Bossio, A.; Monetta, T.; Bellucci, F.; Lignola, G.P.; Prota, A. Modelling of concrete cracking due to corrosion process of reinforcement bars. Cem. Concr. Res. 2015, 71, 78-92. [CrossRef]

26. Maslehuddin, M.; Allam, I.A.; Al-Sulaimani, G.J.; Al-Mana, A. Effect of rusting of reinforcing steel on its mechanical properties and bond with concrete. Mater. J. 1990, 87, 496-502.

27. Shi, J.J.; Sun, W. Recent research on steel corrosion in concrete. J. Chin. Ceram. Soc. 2010, 38, 1753-1764.

28. Yu, B.; Liu, J.B.; Chen, Z. Probabilistic evaluation method for corrosion risk of steel reinforcement based on concrete resistivity. Constr. Build. Mater. 2017, 138, 101-113. [CrossRef]

29. Hong, S.; Wiggenhauser, H.; Helmerich, R.; Dong, B.; Dong, P.; Xing, F. Long-term monitoring of reinforcement corrosion in concrete using ground penetrating radar. Corros. Sci. 2017, 114, 123-132. [CrossRef]

30. Tondolo, F. Bond behaviour with reinforcement corrosion. Constr. Build. Mater. 2015, 93, 926-932. [CrossRef]

31. Dong, Z.P.; Niu, D.T.; Pi, X.X. The experimental research on the conditions for occurrence of initial corrosion of steel bar within concrete under atmospheric environment. Ind. Constr. 2001, 31, 3-5.

32. Fan, Y.F.; Zhou, J.; Huang, Z.G. Experimental research on strength of R. C. member corroded by chloride. Ind. Constr. 2001, 31, 3-5.

33. Fan, Y.F.; Huang, Z.G.; Li, J.M. Research on cohesive property between reinforcement and concrete of corroded R. C. member. Ind. Constr. 1999, 29, 49-51.

34. Yuan, Y.S.; Fu, F.P.; Cai, Y. The structural behavior deterioration model for corroded reinforced concrete beams. China Civ. Eng. J. 2001, 3, 47-52.

35. Okada, K.; Kobayashi, K.; Miyagawa, T. Influence of longitudinal cracking due toreinforcement corrosion on characteristics of reinforced concrete member. Aci Struct. J. 1988, 85, 134-140. 
36. Castel, A.; François, R.; Arliguie, G. Mechanical behaviour of corroded reinforced concrete beams-Part 2: Bond and notch effects. Mater. Struct. 2012, 33, 545-551. [CrossRef]

37. Berra, M.; Castellani, A.; Coronelli, D.; Zanni, S.; Zhang, G. Steel-concrete bond deterioration due to corrosion: Finite-element analysis for different confinement levels. Mag. Concr. Res. 2000, 55, 237-247. [CrossRef]

38. Al-Majidi, M.H.; Lampropoulos, A.P.; Cundy, A.B.; Tsioulou, O.T.; Alrekabi, S. Flexural performance of reinforced concrete beams strengthened with fibre reinforced geopolymer concrete under accelerated corrosion. Structures 2019, 19, 394-410. [CrossRef]

39. Mircea, D.; Ioani, A.; Filip, M.; Pepenar, I. Long-term durability of reinforced and prestressed elements in aggressive environments. Aci Mater. J. 1994, 91, 135-140.

40. Wang, X.J. The Deterioration Model and Prediction of R. C. Beam Bridges. Master's Thesis, Tongji University, Shanghai, China, 2006.

41. Zhang, P.S.; Lu, M.; Li, X.Y. Mechanical property of rustiness reinforcement steel. Ind. Constr. 1995, 9, 41-44.

42. Xu, M.T.; Wang, L.K.; Niu, D.T. Verifying analysis of the model of steel corrosion in reinforcement concrete. J. Xi'an Univ. Archit. Technol. (Nat. Sci. Ed.) 1999, 31, 127-130.

43. Castel, A.; Frangois, R.; Arliguie, G. Mechanical behaviour of corroded reinforced concrete beams-Part 1: Experimental study of corroded beams. Mater. Struct. 2000, 33, 545-551. [CrossRef]

44. Duan, S.L. Study on Safety Evaluation Method of Tunnel Supporting Structure Based on Characteristics of Cracked Concrete; Southwest Jiaotong University: Chengdu, China, 2013.

45. Mak, M.W.T.; Desnerck, P.; Lees, J.M. Corrosion-induced cracking and bond strength in reinforced concrete. Constr. Build. Mater. 2019, 208, 228-241. [CrossRef]

46. Abosrra, L.; Ashour, A.F.; Youseffi, M. Corrosion of steel reinforcement in concrete of different compressive strengths. Constr. Build. Mater. 2011, 25, 3915-3925. [CrossRef]

47. Wuhan Corr Test Instruments Co., Ltd. Corr Test Electrochemical Test System Instructions; Wuhan Industry: Wuhan, China, 2012.

48. Wu, Q.; Yuan, Y.S.; Zhu, J. Experimental Research on the Performance Degradation of Corroded Reinforced Concrete Compression and Bending Members. J. China Univ. Min. Technol. 2010, 39, 843-848.

49. Li, F.; Yuan, Y.S. Effects of corrosion on bond behavior between steel strand and concrete. Constr. Build. Mater. 2013, 38, 413-422. [CrossRef]

50. Zhao, Y.X.; Jin, W.L. Test study on bond behavior of corroded steel bars and concrete. J. Zhejiang Univ. 2002, 4, 8-12.

51. Dong, Y.G.; Lv, X.L.; Yang, X.C. Overview of bond-Slip research on steel reinforced concrete structures. Struct. Eng. 2005, 21, 82-87.

52. Hobbs, D.W. Chloride Ingress and Chloride-Induced Corrosion in Reinforced Concrete Members, Corrosion of reinforcement in concrete construction. R. Soc. Chem. 1996, 183, 124-135.

(C) 2020 by the authors. Licensee MDPI, Basel, Switzerland. This article is an open access article distributed under the terms and conditions of the Creative Commons Attribution (CC BY) license (http://creativecommons.org/licenses/by/4.0/). 